\title{
Studying Acculturation using Transactional Analysis Theory: the Interplay between Existential Positions and Acculturation Styles
}

(C) 2011 Lena Kornyeyeva

\begin{abstract}
This article is a partial report about quantitative research on the role of the Negative Existential Position in Authoritarian Personality formation (reported on elsewhere) and acculturation features among immigrants with authoritarian backgrounds in a democratic milieu (Germany). Data were collected among respondents of different backgrounds: immigrants in Germany from Turkey, the former Soviet Union and Western countries, and native Germans as a quasi-control group ( $N=1318)$, with each subsample encompassing at least 200 respondents. Various statistical analyses were performed in order to validate the empirical outcomes (from correlation analysis to structural equation modelling). The hypothesis that a Negative Existential Position is more articulated among individuals who were exposed to an authoritarian socialization was confirmed. The hypothesis that a Negative Existential Position serves as a predictor for the so called Acculturation Dysfunction was confirmed as well. The conceptual analogy between Existential Positions and Styles of Acculturation was examined and the hypothesis that four possible styles of acculturation (Berry et al., 1987, Berry \& Kim, 1988; Berry et al., 1989) are correlated with correspondent Existential Position found support.
\end{abstract}

\section{Key words}

Acculturation, Acculturation Styles, Acculturation Dysfunction, Existential Position, Transactional Analysis

\section{Introduction}

In recent years acculturation has become one of the most widely researched areas worldwide. European countries nowadays are dependent on migrants and will undoubtedly continue to need immigration (Eurostat, 2006). A significant proportion of newcomers continue to be immigrants from countries with an authoritarian legacy (whether from secular cultures or traditionalistic, religiously-structured such as some Islamic countries). Managing immigration and integration of immigrants is one of the most challenging tasks the European Union is facing today (Guild \& van Selm, 2005). Experience of insufficient integration of past immigrants together with concern about rising support of the far right are the two principal factors which have led to pressure for a more effective EU strategy to promote the social, economic, cultural, and political integration of migrants and their next generations (Spencer, 1994, 2003).

The overall goal of the research was to investigate problems of acculturation among young immigrants (1835 year old) from ex-Soviet countries and Turkey to Germany as a host society. The acculturation features of ex-Soviet immigrants to Germany were compared to acculturation features among immigrants from Turkey, in order to find common and non-common characteristics of the acculturation strategies among ex-Soviet and Turkish immigrants. To gather more information on it and to be able to compare acculturation features of immigrants with authoritarian backgrounds with the acculturation features of immigrants and sojourners without authoritarian backgrounds, a group of respondents from Western countries was also surveyed.

One of the central assumptions of the entire research was the idea that cultural or religious differences as such do not serve as reasons for the conflicts among different groups or provide difficulties within acculturation in another culture, but that a specific psychological predisposition leads people to be prone to developing conflict with others. In other words, the Negative Existential Position (any of its three types) was hypothesised to have an impact on acculturation strategies of immigrants in a democratic society and specifically on the 'successfulness' of acculturation as it is subjectively perceived by an immigrant. This concept will be explained in greater detail later in this paper. 
The acculturation concept has been in use since 1880, when it was introduced by American anthropologists as a concept of cultural change which happens between two different groups who come into contact with each other (Sayegh \& Lasry, 1993). The first empirical studies on acculturation in anthropology were conducted in 1930; the first classical definition of acculturation was offered in 1936: "Acculturation comprehends those phenomena which result when groups of individuals having different cultures come into continuous first-hand contact, with subsequent changes in the original culture patterns of either or both groups" (Redfield, Linton \& Herskovits, 1936, p. 149). According to Berry (1990) acculturation involves both a process and a state, and results of the process may be relatively stable but may also continue to change in an ongoing process. Berry views acculturation as a bi-directional process with the changes emerging within both (or more as in multicultural societies) groups in contact.

Cross-cultural research (Berry, 1997) investigates the phenomena occuring when individuals socialized within one cultural context face a task of re-socialization in another culture. One of the original thoughts within this research was that the Negative Existential Position may help to explain difficulties within acculturation as a resocialization-like process. Essentially the Negative Existential Position is understood as a conflict with the Self and therefore a prerequisite for conflicts with Others, whilst the acculturation context is by its nature a confrontation with Others.

The core of acculturation approach (Berry, 1980, 1984) is based on two basic issues, which emerge when two (or more) cultures interact: 1 . the measure to which a group tends to maintain its native culture and identity; and 2 . the measure to which a group tends to be engaged in daily interactions with other ethno-cultural groups in the larger society, including the dominant one. Berry's approach to acculturation, used in this study, is a fourfold approach to acculturation. It is based on an assumption that an individual may appreciate, practice or identify with two different cultures independently of one another, and thus manifest one of the four styles of acculturation - Integration, Separation, Assimilation or Marginalization.

Conceptual independence of these four styles of acculturation has been empirically demonstrated in a number of studies (e.g., Ben-Shalom \& Horenczyk, 2003; Ryder, Alden \& Paulhus, 2000). In brief, in the acculturation context the larger society's culture and the native culture can both have a positive or negative valence for an immigrant, representing positive or negative attitudes, attachment, and identification with each of the cultures. Generally this can be considered as acceptance (labelled as ' + ') or rejection (labelled as '-') of each culture, as shown in Figure 1.
Figure 1: Scheme of the fourfold taxonomy of acculturation styles. Positive and negative attitudes concerning the Native culture and the Host culture create four generic styles of acculturation

\begin{tabular}{|c|c|}
\hline INTEGRATION & SEPARATION \\
\hline My culture + & My culture + \\
\hline Host culture + & Host culture - \\
\hline My culture - & My culture - \\
\hline Host culture + & Host culture - \\
\hline ASSIMILATION & MARGINALIZATION \\
\hline
\end{tabular}

Within this approach four main domains of acculturation are usually measured to identify an immigrant's style of acculturation. These main domains encompass native/ host society's language-, holidays-, family- and general culture-related issues. The measurements are mostly done using Likert-scale items (statements) about attitudes and practices on these four acculturation related domains. This study followed this tradition. In addition four original items on Marginalization were created, pre-tested and used in the study.

One of the core TA concepts, the Existential Position is also understood as a double-dimensional concept, which encompasses simultaneously attitude toward Self and Others. Positive and negative attitudes concerning Self and Others create four generic Existential Position types. As shown in Figure 2, this fourfold approach to Self-conception resembles an approach to acculturation, which encompasses simultaneously two attitudes as well (toward a native and a receiving culture).

Figure 2: Scheme of the Conceptual Congruence among the Existential Positions and the Styles of Acculturation

\begin{tabular}{|c|c|}
\hline (INTEGRATION) & (SEPARATION) \\
\hline $\begin{array}{l}\text { Positive Existential } \\
\text { Position }\end{array}$ & $\begin{array}{r}\text { Negative Existential } \\
\text { Position } 1\end{array}$ \\
\hline $\mathrm{Iam}+$ & $\mathrm{Iam}+$ \\
\hline You are + & You are - \\
\hline I am - & I am - \\
\hline You are + & You are - \\
\hline (ASSIMILATION) & (MARGINALIZATION) \\
\hline $\begin{array}{l}\text { Negative Existential } \\
\text { Position } 2\end{array}$ & $\begin{array}{r}\text { Negative Existential } \\
\text { Position } 3\end{array}$ \\
\hline
\end{tabular}


Thus, integration as the most 'harmonious' style of acculturation resembles the only positive Existential Position 'I am OK - You are OK'; Separation resembles 'I am OK - You are NOT OK' Position (retention of one's own culture - rejection of a new culture); Assimilation resembles 'I am NOT OK - You are OK' Position (loss of one's own culture - acceptance of a new culture); and marginalization resembles 'I am NOT OK - You are NOT OK' Position (loss of one's own culture - rejection of a new culture).

\section{Aims of the Research}

Acculturation strategies, according to Berry, encompass both attitudes and actual behaviors of immigrants (as they include both the preferences and the outcomes) that are manifested in day-to-day intercultural encounters (Berry, 1989, Sam \& Berry, 2006). This research set out to examine not just how styles of acculturation are manifested in different immigrant groups but also to investigate subjectively perceived 'successfulness' of the acculturation process as it is seen by an immigrant and in a way the motivational aspects of acculturation.

Moreover, in a quantitative research like this one, an operationally measurable concept was needed which could be examined as a dependent variable in statistical data analysis. Therefore the concept of Acculturation Dysfunction was implemented for this particular research. Among immigrants, Acculturation Dysfunction is a phenomenon of unsuccessful acculturation within another culture; lingering difficulties in acceptance (or non-acceptance per se) of value system, rules, norms, ethics and patterns of relationships which are customary to a host society. It is accompanied by any of three 'inharmonious' acculturation styles, but deals with the emotional and motivational aspects of acculturation rather than the cognitive and behavioural ones.

It was hypothesised that the concepts of acculturation style and Existential Position could be regarded as congenial. Namely, Positive Existential Position is conceptually close to Integration, I am OK - You are NOT OK Position is conceptually close to Separation, I am NOT OK - You are OK Position is conceptually close to Assimilation, I am NOT OK - You are NOT OK Position is conceptually close to Marginalization.

Another assumption was made about the relationships between the Negative Existential Position and acculturation and the Negative Existential Position and two of its supposed predictors - family and society with authoritarian features. Thus it was hypothesized that the Negative Existential Position serves as a predictor of difficulties within the acculturation process and that the Negative Existential Position in its turn is a 'product' of authoritarian socialization (i.e. the product of influence of the two main institutions of socialization - family and culture). It was also hypothesised that each type of the three Negative Existential Positions would predict the dysfunctional acculturation in another culture to a certain degree. The task was to examine the causal relationships and the degree to which different types of the Negative Existential Positions predict the difficulties within acculturation.

\section{Methods}

Sample

The research was designed as a comparative quantitative research; four groups of adult residents of Germany were under investigation: two groups with an authoritarian socialization background (Turkish migrants, $N=206$, and migrants from the former Soviet Union, $N=223$ ) and one group without authoritarian socialization background (migrants or sojourners from Western countries, $\mathrm{N}=304$ ) (Table 1).

Empirical data collection was conducted among foreign residents of different statuses in Germany during the years 2007-2009. Among respondents were immigrants, visiting students and academics, guest workers (mostly among Turks or Ex-Soviets) or self-employed individuals (mostly among Westerners), sojourners, ethnic German repatriates from Kazakhstan or Russia ('Russian Germans'), young native Turkish women who got married to 'German Turks', etc. For methodological reasons, a minimum of 200 respondents from each group had to be sampled. The group sizes, however, turned out to be unequal due to a limited approachability (and sometime unwillingness to participate) of participants in the survey: young Turks who came to Germany as adults were the most difficult group to include within the survey.

The survey was implemented by means of a standardized questionnaire of sixty-nine items, comprising six scales and a number of demographic questions such as age, education, religious affiliation, etc. The psychometric part of the questionnaire was structured with a bipolar five-point Likert scale (with options from "I totally agree with this statement" to "I totally disagree with the statement"). The surveying was completely anonymous and needed no further contact with a respondent. The questionnaire was available in Turkish, Russian, English and German and participants were encouraged to take the version in their mother tongue in order to reduce possible misleading interpretations. Translation and back translations of the questionnaire were made; before the field part of the survey a pre-test was conducted involving participants with corresponding cultural backgrounds. From the larger amount of items the most reliable were selected for the final edition of the questionnaire which was used in the survey. 


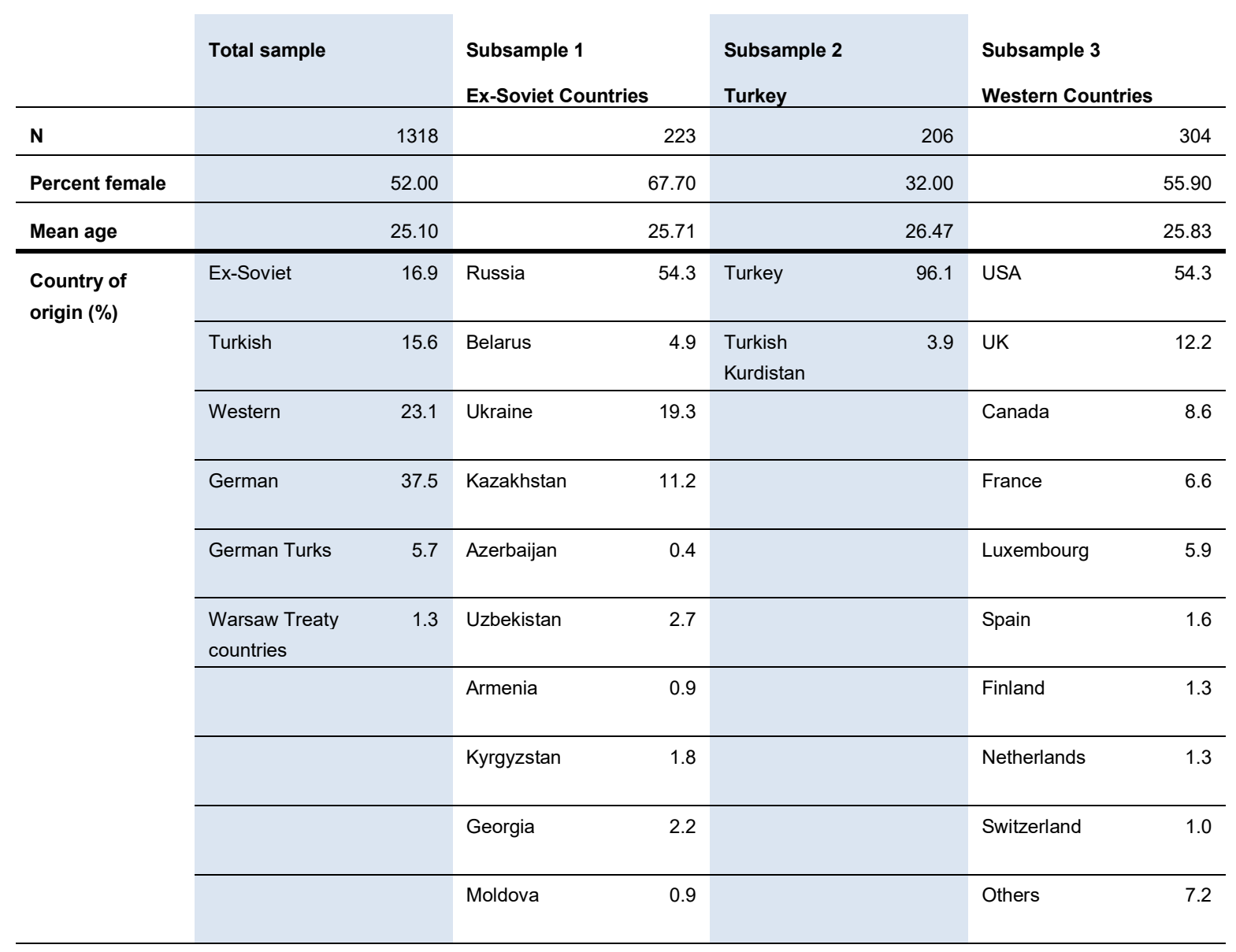

Data were collected via online surveying as well as face-to-face contacts with participants. In the statistical data analysis only responses of 18 - 35 year old participants were used; one of the core conditions was that the non-German participants were socialized in their home countries and came to Germany not younger than at 15 years of age. Statistical analyses were performed in SPSS and Amos, a structural equation modelling software.

\section{Ethics}

The research design was elaborated conjointly with Prof. Klaus Boehnke, and was approved by four other supervising professors: two internal ones (Prof. Chris Welzel and Prof. Ulrich Kühnen (School of Humanities and Social Sciences, Jacobs University Bremen, Germany) and two external ones (Prof. John W. Berry (Department of Psychology, Queen's University at Kingston, Canada) and Prof. Henning Schulze (Hochschule Deggendorf, Germany). The ethical aspect of the surveying was in conformity with the German current Privacy Policy in Science and Research Law ("Datenschutz in Wissenschaft und Forschung").
All the participants took part in the survey voluntarily; the questionnaire was anonymous; no data collected in this survey has been transferred to a third party. The questionnaire was opened with the following introductory text: Dear respondent, this survey is a part of an investigation of general public opinion concerning a variety of social issues. When answering the questions below, please remember that there are no right or wrong answers; the only thing that matters is your personal opinion. This study is conducted anonymously; demographic data (like age, religious affiliation or education) are asked only for statistical purposes.

\section{Scales used in the study}

The instruments of measurement were partially extracted from existing valid instruments and partially developed in cooperation with the first supervisor of the research thesis. The part of the research reported in this article involved the following scales:

1. Perceived Authoritarian Parenting Scale (Authoritarian Family) to evaluate degree of familial authoritarianism as a micro-societal socialization factor. 
The items were extracted from the original Lederer at al (1991) authoritarian attitude measurement scale published in German. Examples: "My parents believe that a child should have strict discipline in order to develop a fine strong character." and "It usually helps the child in later years if he is forced to conform to his parents' ideas."

2. Perceived Authoritarian Cultural Background Scale to evaluate the degree of influence of authoritarian-like cultural aspects on personality within the socialization process as a macro-societal factor. These items were developed in cooperation with the first supervisor of this thesis. Examples: "In my home country's culture it is customary to think "To be afraid of someone means to respect him." and "In my school time teachers were never contradicted and criticized.".

3. Acculturation Dysfunction Scale to measure a level of subjectively perceived ability to adjust to a new societal environment. Some items for this scale were developed on the basis of 4-Item-Short-AcculturationTest (Wallen, Feldman, \& Anliker, 2002) and Sociocultural Adaptation scale, (Ward \& Kennedy, 1999). Some items of this subscale were developed in cooperation with the first supervisor of this thesis. Examples: "I would wish my children to live in this country." and "Here in Germany I am enjoying my life much more than I was in my home country."

4. Existential Position Scale used primarily of an individual's tendency toward any of the four Existential Positions. The items were extracted from a multidimensional questionnaire of individuality Das Egogramm (originally in German) developed by Karl Kälin (Kälin \& Müri, 1993). Examples: "I am convinced that human beings are capable to lead and to control themselves and thus to develop their potential." and "In many situations I feel inferior to others." For this particular study a statistical measurement tool had to be developed and certain calculations had to be made so the Existential Position variables were calculated as index variables; this was also because both I-scale and Youscale have both positive and negative values as shown in Figure 3. Thus, a maximum possible score on the positive domain ('I/You - OK') is 4 , a maximum possible score on the negative domain ('I/You - NOT OK') is - 4; any positive score corresponds to a degree of the Positive Existential Position and any negative sore corresponds to a degree of the Negative Existential Position.

5. Acculturation Style Scale for integration, assimilation and separation. 12 items were partially extracted from the questionnaire developed by Berry et al. (Berry et al., 1987, Berry \& Kim, 1988; Berry, et al., 1989); four items for marginalization measurement were developed originally in cooperation with the first supervisor of this thesis, as they were lacking in the current empirical research in the field. Examples: "We should maintain our homeland's distinctive culture, and adopt the German culture at the same time." and "We live in Germany and we should give up our native culture and our old habits; we should adopt the German way of life - to think and act as Germans."

The hypothesised relationships between the Existential Position and the Acculturation Style concepts required special attention. The presumption was checked within pre-test and ended with positive results; further calculations are reported under Empirical Findings.

Figure 3: Four types of Existential Position, measured from 1 to 4 (on the positive parts of axis) and -1 to -4 (on the negative ones). I-scale expressed in the $y$-axis and You-scale expressed in the $x$-axis

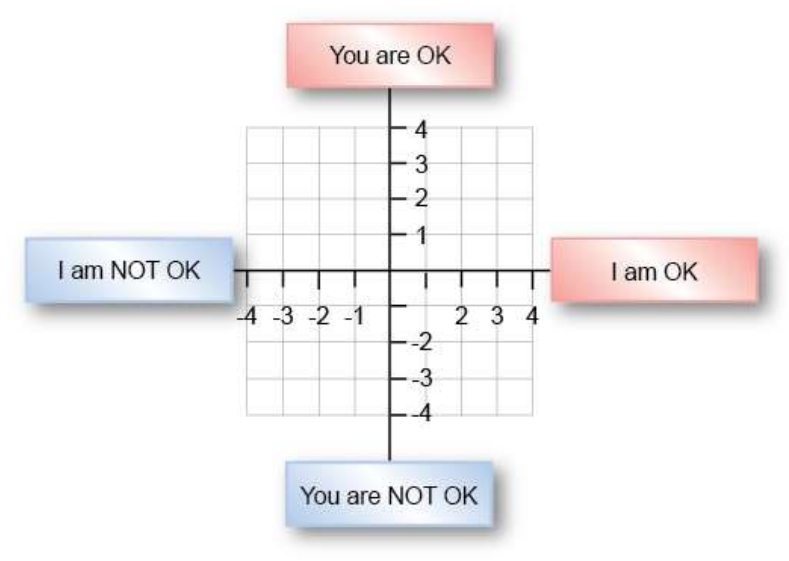

\section{Research design}

There were two models examined in the research, of which the first is reported on within this paper. This is of the interplay between the styles of acculturation and the conceptually correspondent types of the Existential Position and is shown in Figure 4. The main assumption was that they are to a certain degree positively correlated, and that Integration is not related with Acculturation Dysfunction whereas the other three styles of acculturation will be.

The other research model is depicted in Figure 5 and expresses the idea that the Acculturation Dysfunction is predicted by the Negative Existential Position, which has its roots in two main socialization agents - family and culture. This work is reported in another article by the author (Kornyeyeva, O. in print). A more detailed report on the research is also given in the author's dissertation thesis which is available as an e-book (Kornyeyeva, O. 2010).

The Authoritarian Family variable in this model encompassed the Authoritarian Parenting Style items, i.e. a level of authoritarianism in a family of upbringing, as it is subjectively perceived by a respondent. The subjectively perceived authoritarianism of the culture of upbringing encompassed a wider society and a culture, beyond the family of upbringing. Under the 
Negative of Existential Position in this model any of the three types of Negative Existential Positions are understood and all of them were designed to be examined within the data analysis. The Acculturation Dysfunction, as mentioned previously, is understood as subjectively perceived difficulties in acculturation, which are accompanied by any of three 'inharmonious' acculturation styles; it deals mostly with emotional and motivational aspects of acculturation rather than cognitive and behavioural ones.

Figure 4: The idea of (inter)relatedness among the four Existential Positions and four Styles of Acculturation and with the Acculturation Dysfunction.

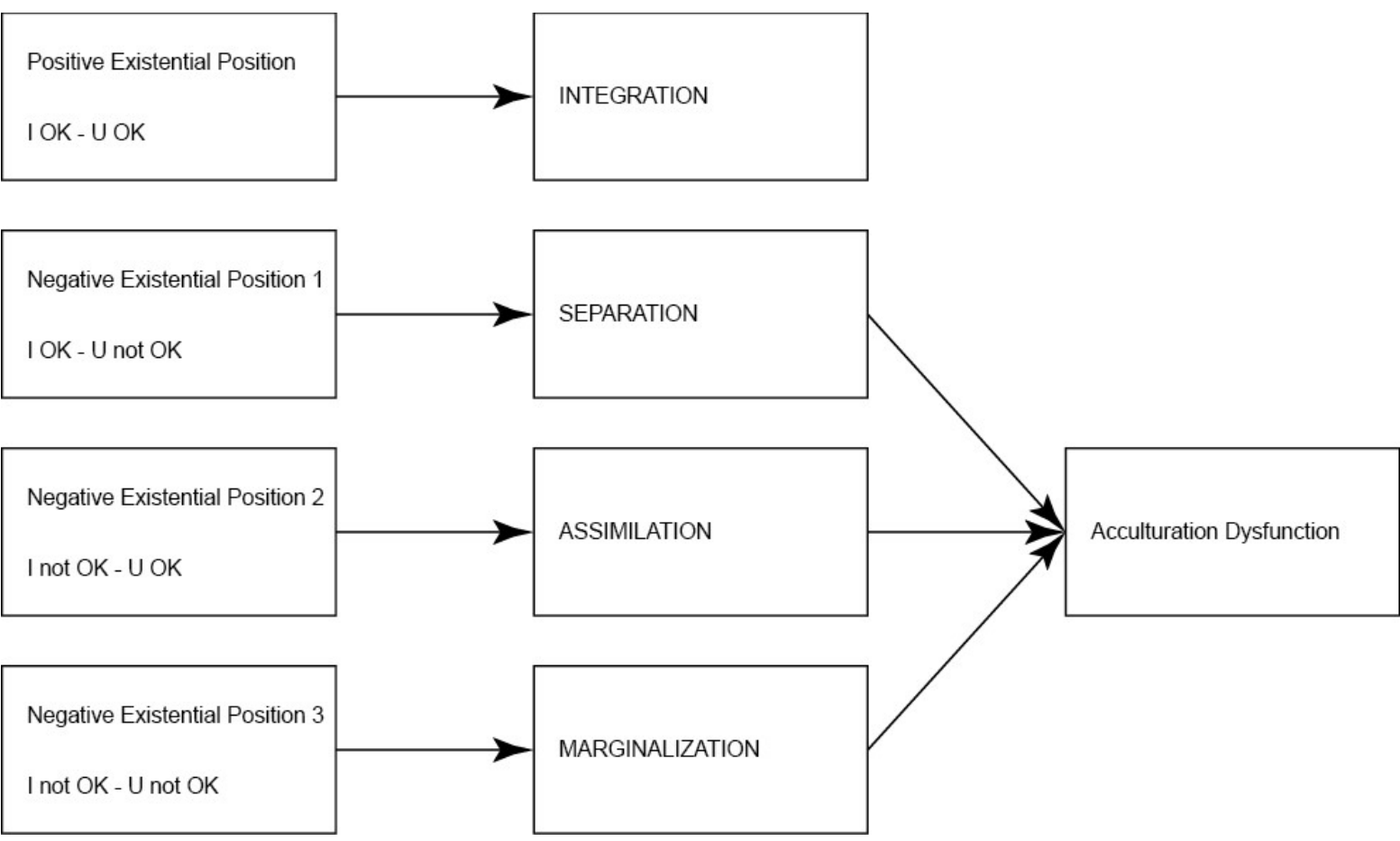

Figure 5: Acculturation Dysfunction predicted by the Negative Existential Position.

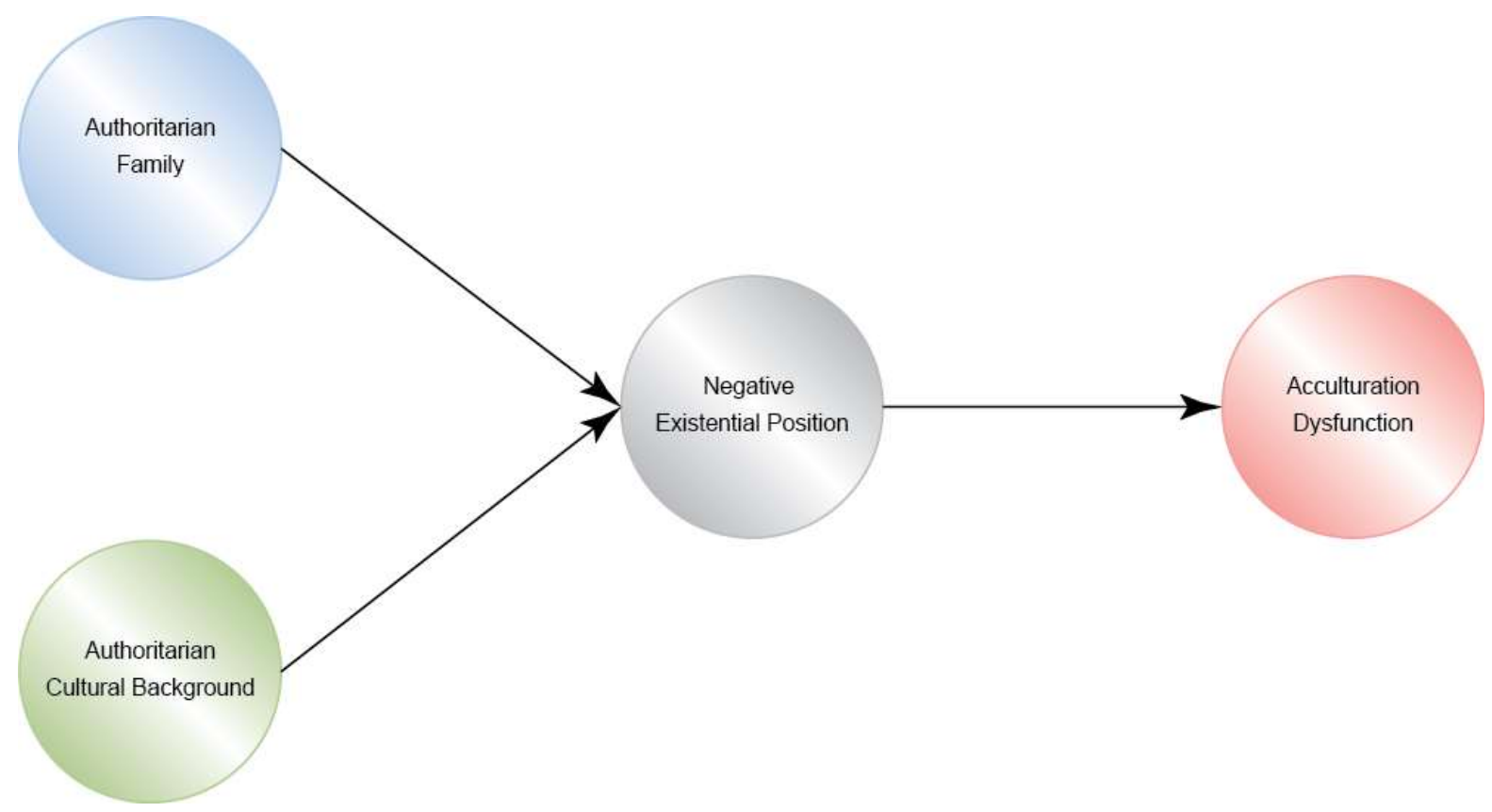




\section{Empirical Findings}

Statistical data analysis began with an assessment of prevailing acculturation style among the three immigrants' groups. As Table 2 shows, there were higher mean scores on the 'inharmonious' styles of acculturation (Separation, Assimilation and Marginalization) with Separation being particularly high in the Turkish subsample compared to the Ex-Soviet and Westerner subsamples. At the same time, Integration, as the only 'harmonious' style of acculturation, was the most articulated for all three subsamples.

Table 2: Mean Scores on Four Styles of Acculturation among Immigrant Subsamples under Scrutiny

\begin{tabular}{|c|c|c|c|c|}
\hline \multirow[b]{2}{*}{ Subsample } & \multicolumn{4}{|c|}{ Acculturation Style } \\
\hline & 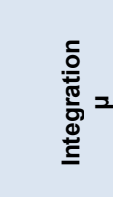 & 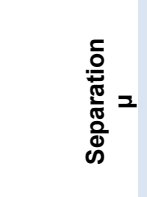 & 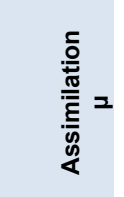 & 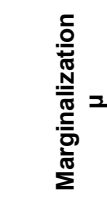 \\
\hline $\begin{array}{l}\text { Ex-Soviet } \\
(\mathrm{N}=223)\end{array}$ & 16.74 & 9.16 & 7.10 & 10.70 \\
\hline $\begin{array}{l}\text { Turkish } \\
(\mathrm{N}=199)\end{array}$ & 14.58 & 12.05 & 9.65 & 11.00 \\
\hline $\begin{array}{l}\text { Western } \\
(N=303)\end{array}$ & 15.80 & 8.54 & 8.27 & 10.58 \\
\hline
\end{tabular}

One-way ANOVA with post hoc comparison (Dunnett's T3) was used. There were statistically significant differences among the Ex-Soviet, Turkish and Western subsamples on the Integration variable. On the Separation variable there were no differences between Ex-Soviet and Western subsamples $(p=.091)$, but there was a difference between Ex-Soviet and Turkish and Turkish and Western subsamples. This ANOVA test was statistically significant $(p<.001)$ on both Between group comparisons and Within group comparisons and also on the Homogeneity of Variances $(p<.001)$. These descriptive results were however 'corrected' by additional information found by means of auxiliary items in the questionnaire like "Do you intend to stay in Germany as a permanent resident?", "Do you intend to move to another country?" and "Do you intend to move back to your home country?" with 'yes' or 'no' options and How do you feel deep inside? with four possible options: "mostly as a person from the country in which I grew up", "mostly as a German", "as both" and "as neither". More detailed information on these analyses is given in the dissertation thesis (Kornyeyeva, O. in print).

The mean scores on the four Existential Position types were estimated for all subsamples. As Table 3 shows, the highest mean score on the Negative Existential Position type was found in the Turkish subsample, while the lowest (the more close to the Positive Existential Position) was found in the German subsample. The ExSoviet subsample scored as the second highest group after the Turkish subsample.

Table 3: Mean Scores on the Negative Existential Position Variables across the Subsamples

\begin{tabular}{|c|c|c|c|}
\hline \multirow[b]{2}{*}{$\begin{array}{l}\text { Subsample/ } \\
\text { Variable }\end{array}$} & \multicolumn{3}{|c|}{$\begin{array}{l}\text { Type of Negative } \\
\text { Existential Position }\end{array}$} \\
\hline & 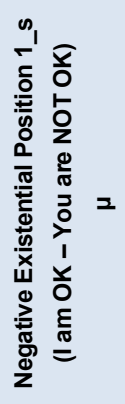 & 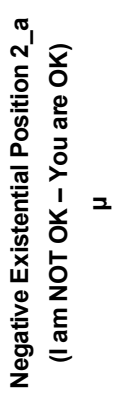 & 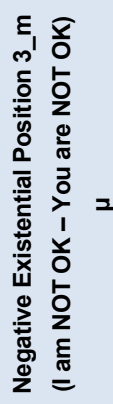 \\
\hline $\begin{array}{l}\text { Ex-Soviet } \\
(\mathrm{N}=223)\end{array}$ & 28.90 & 24.83 & 23.43 \\
\hline $\begin{array}{l}\text { Turkish } \\
(\mathrm{N}=198)\end{array}$ & 29.52 & 25.65 & 24.59 \\
\hline $\begin{array}{l}\text { Western } \\
(N=304)\end{array}$ & 27.61 & 24.08 & 21.63 \\
\hline
\end{tabular}

The correlations between the pairs were calculated and the hypothesis about congeniality of the Existential Position and the (corresponding) styles of acculturation was confirmed: all the correlations were positive and statistically significant, as shown in Table 4.

Table 4: Correlations between Existential Position Index Variables and Berry's Acculturation Styles (for the total immigrant sample, $N=723$ )

\begin{tabular}{|c|c|c|c|c|}
\hline 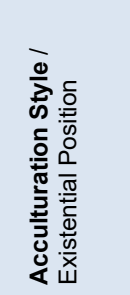 & 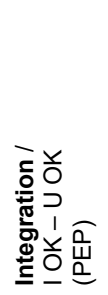 & 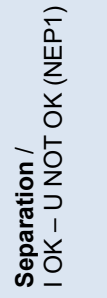 & 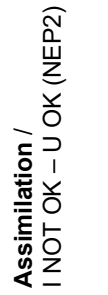 & 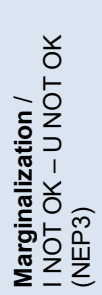 \\
\hline Pearson & & & & \\
\hline Correlation & 0.247 & 0.181 & 0.162 & 0.234 \\
\hline $\mathrm{p}$ (2-tailed) & $p<.001$ & $p<.001$ & $p<.001$ & $p<.001$ \\
\hline$N$ & 723 & 723 & 723 & 723 \\
\hline
\end{tabular}

In order to examine the assumption on the relationships among the types of Existential Position and different styles of acculturation, a correlation analysis was 
performed for each of the subsamples. Generally, among all three types of the Negative Existential Position, the strongest positive correlations were documented between the Negative Existential Position 3 and the three 'inharmonious' styles of acculturation - Separation, Assimilation and Marginalization for most of the subsamples as well as for the total immigrant sample, as shown in Table 5.

Table 5: Correlations among the Styles of Acculturation and the Negative Existential Position 3

\section{Style of Acculturation}

\begin{tabular}{|c|c|c|c|c|c|}
\hline $\begin{array}{l}\text { Negative } \\
\text { Existentia } \\
\text { Positions }\end{array}$ & & 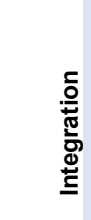 & 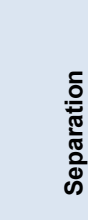 & 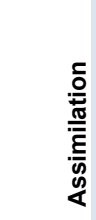 & 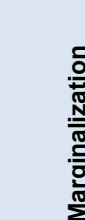 \\
\hline \multirow{3}{*}{$\begin{array}{l}\text { Immi- } \\
\text { grants' } \\
\text { Total } \\
\text { Sample }\end{array}$} & $r$ & -.106 & .371 & .203 & .244 \\
\hline & $\begin{array}{l}\mathrm{p}(2- \\
\text { tailed })\end{array}$ & .004 & $<.001$ & $<.001$ & $<.001$ \\
\hline & $\mathrm{N}$ & 724 & 723 & 728 & 727 \\
\hline \multirow{3}{*}{$\begin{array}{l}\text { Ex- } \\
\text { Soviet }\end{array}$} & $r$ & -.125 & .380 & .090 & .165 \\
\hline & $\begin{array}{l}\mathrm{p}(2- \\
\text { tailed })\end{array}$ & .063 & $<.001$ & .182 & .014 \\
\hline & $\mathrm{N}$ & 222 & 222 & 222 & 222 \\
\hline \multirow[t]{3}{*}{ Turkish } & $r$ & -.128 & .420 & .421 & .388 \\
\hline & $\begin{array}{l}\mathrm{p}(2- \\
\text { tailed })\end{array}$ & .089 & $<.001$ & $<.001$ & $<.001$ \\
\hline & $\mathrm{N}$ & 179 & 180 & 183 & 183 \\
\hline \multirow[t]{3}{*}{ Western } & $r$ & -.040 & .204 & .067 & .163 \\
\hline & $\begin{array}{l}\mathrm{p}(2- \\
\text { tailed })\end{array}$ & .494 & $<.001$ & .248 & .005 \\
\hline & $\mathrm{N}$ & 300 & 298 & 300 & 299 \\
\hline
\end{tabular}

Such an empirical finding was expected to be found, because the Negative Existential Position 3 'I am NOT OK - You are NOT OK' is conceptually the only 'pure' Negative Existential Position because it does not include a positive aspect, which in the other two Negative Existential Positions is 'contaminating' the variable in the analysis (it is difficult to distinguish how much positiveness/negativeness is attributed to each of the parts of the Self-conception).

Correlations between the styles of acculturation and the types of Existential Position were examined for each of the subsamples under investigation. They were found to be of different strengths and not statistically significant in all cases (although very close to significance in some cases). As shown in Figure 6, statistically significant positive correlations were found between Integration variable and Positive Existential Position for Ex-Soviet, Turkish and Western subsamples; between Assimilation variable and Negative Existential Position 2 variable for the Turkish subsample and between Marginalization variable and Negative Existential Position 3 variable for the Ex-
Soviet and the Turkish subsamples. These finding are indicative of the conceptual closeness theoretically assumed between the (corresponding) styles of acculturation and the types of the Existential Position. The fact that the results found in the Westerners subsample were the least correlated leaves room for discussion. And the fact that the strongest statistically significant correlations in all three subsamples were found to be with regard to the Integration - Positive Existential Position speaks for the assumed conceptual similarity between the ideas, and suggests that the Negative Existential Position can be 'situationally' expressed in any of the three types, but can be regarded as the holistic idea of the Negative Existential Position where it does not matter which component of it can be identified as 'negative' - 'I am' or 'You are' or both.

To test and validate the obtained correlation results, a structural equation modelling (SEM) approach utilizing AMOS 17.0 was pursued. As the subsamples under investigation were not large enough for structural equation modelling with latent variables, a manifest variable model was tested. Also the data set originally had missing values (although a small number), which regularly creates problems in SEM. Thus, multiple imputation of missing values was implemented and unbiased parameter estimates were created. In this and all further SEM reports standardized coefficients are documented. SEM was implemented in order to examine the causal relationships among the variables on acculturation styles and the Existential Positions and their relationships with the Acculturation Dysfunction variable. The model with standardized coefficients is depicted in figure 6. The Main Model Fit characteristics were as follows: $\mathrm{CMIN} / \mathrm{DF}=2.619, \mathrm{NFI}=.988, \mathrm{CFI}=.992, \mathrm{RMSEA}=.047$.

As depicted in Figure 7, the predictability power of the Existential Positions with regard to the styles of acculturation was confirmed, although the predictability potential was not equally distributed among all types of Existential Positions. As was expected, the Positive Existential Position was found to be a predictor for Integration (.23) and Assimilation (even stronger: .47). An interesting result was found with regard to the 'I am OK - You are NOT OK' Position variable: there was no statistically significant result on its predictability power with regard to the Separation variable, as had been originally expected. At the same time, 'I am NOT OK You are OK' Position was found to be negatively predictive for both the Separation variable (with the coefficient -.19) and the Assimilation variable (with coefficient -.53). It means that the more the 'I am NOT OK - You are OK' Position is articulated the less it determines Separation and Assimilation. The 'I am NOT OK -You are NOT OK' Position showed sufficient predictability power (.25) with regard to the Marginalization variable, and, what had not been assumed, it seems to be predicting Assimilation (.86) and Separation (.36). 
Figure 6: Correlations between Existential Positions and Acculturation Styles among the three subsamples under investigation. ${ }^{*}$ indicates the statistically significant results.

\section{Ex-Soviet $\quad$ Turkish $\quad$ Western \\ sample $(N=223) \quad$ sample $(N=183) \quad$ sample $(N=306)$}

\begin{tabular}{|l|r|r|}
\hline Positive Existential Position & $.335^{\star}$ & $.316^{*}$ \\
\cline { 2 - 3 } I OK - U OK & & \\
INTEGRATION
\end{tabular}

\begin{tabular}{|l|ll|l|}
\hline Negative Existential Position 1 & .152 & .112 & .062 \\
\cline { 2 - 3 } I OK - U not OK & & SEPARATION \\
\hline
\end{tabular}

\begin{tabular}{|l|ll|}
\hline Negative Existential Position 2 & .103 & $.337^{*}$ \\
\cline { 2 - 3 } I not OK - U OK & & .023 \\
\end{tabular}

\begin{tabular}{|l|ll|}
\hline Negative Existential Position 3 & .165 & $.338^{*}$ \\
\cline { 2 - 3 } I not OK - U not OK & & MARGINALIZATION \\
\hline
\end{tabular}

Figure 7: Relationships among the Four Existential Positions and Four Styles of Acculturation and with the Acculturation Dysfunction (with standardized coefficients for the Immigrants' Total Sample, N = 733)

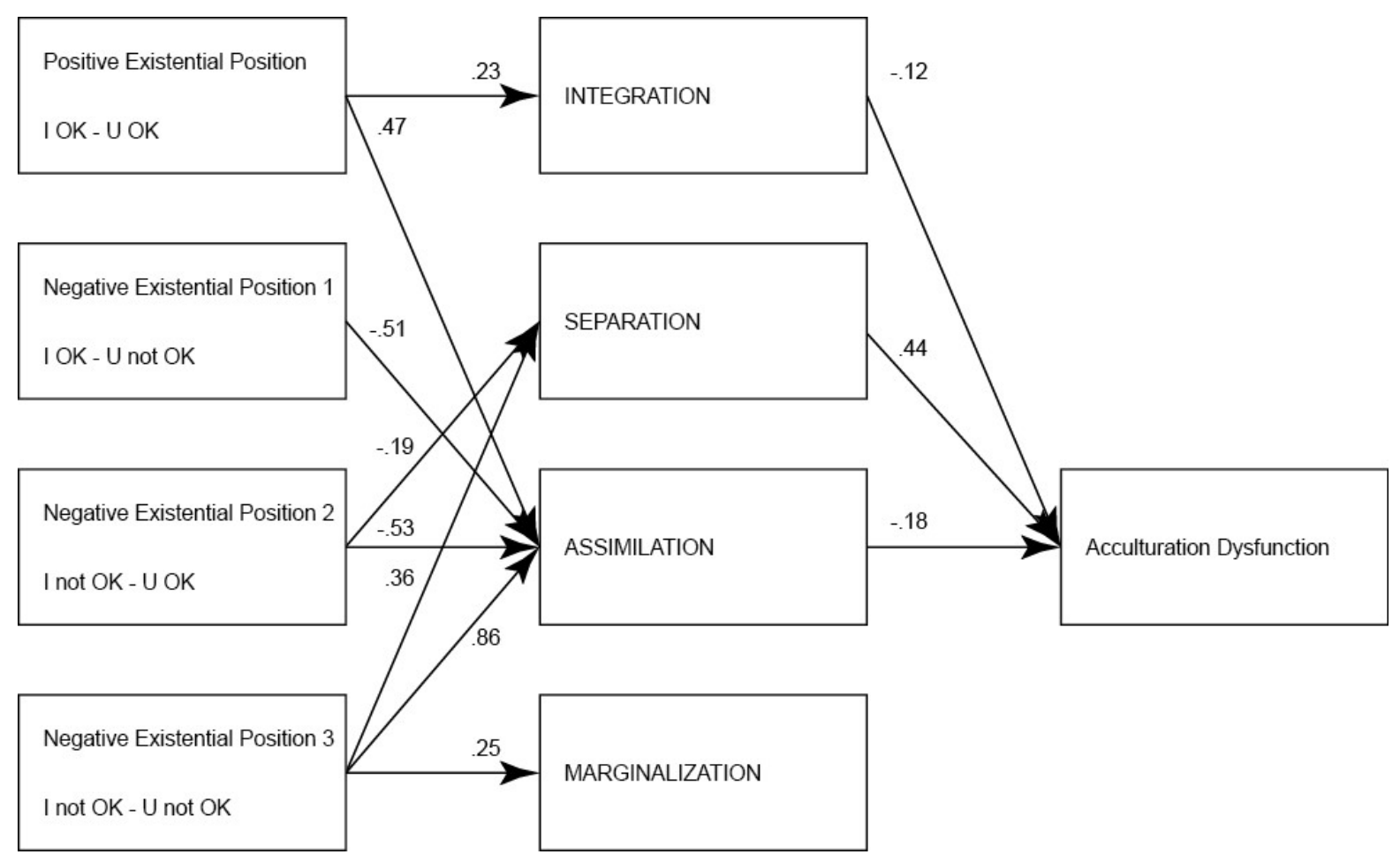


Figure 8: Relationship among the Predictors of the Authoritarian Personality and their Impact on Acculturation Dysfunction (with standardized coefficients for the Immigrants' Total Sample, $N=733$ ).

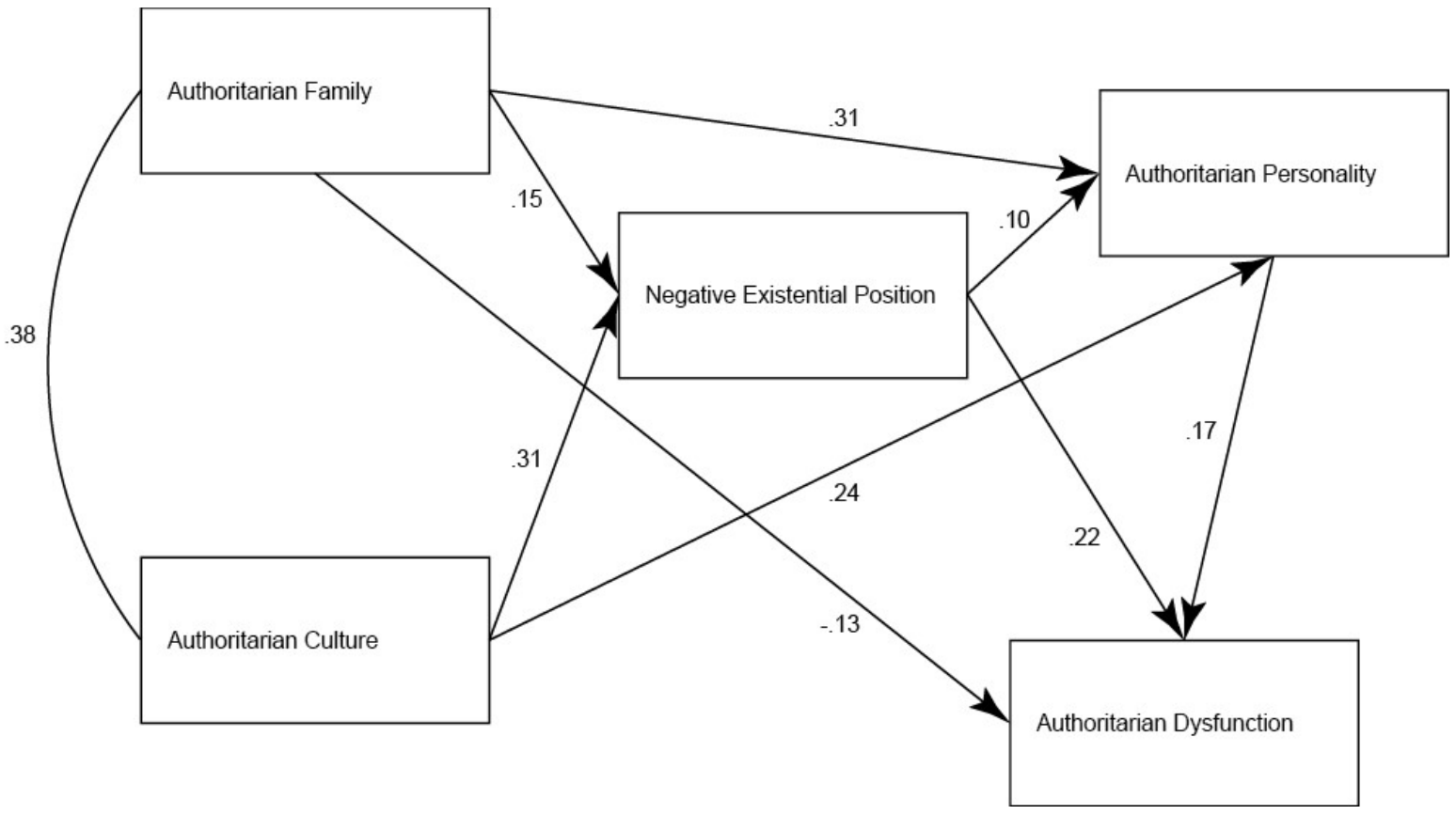

Another set of findings this model encompassed is the causal relationships between the styles of acculturation and the Acculturation Dysfunction. Thus, Integration was found to be a negative predictor of the Acculturation Dysfunction, as was hypothesized (-.12). Interesting is that Assimilation seems to be less 'dysfunctional' in light of its predictability for the Acculturation Dysfunction: it predicts the Acculturation Dysfunction negatively, with coefficient -.18 . Separation, in its turn, appeared to possess a strong predictability potential for the Acculturation Dysfunction (.44).

The last model test in this statistical data analysis documented the relationships between the two background variables (the family of upbringing and the cultural milieu) and the Negative Existential Position and the Acculturation Dysfunction. The model depicted here is the original model from the report of the research made in the dissertation thesis (Kornyeyeva, O. 2010); therefore it includes the Authoritarian Personality variable as well. Relevant in this context, however, are the results on the background variables and their relationships with the Negative Existential Position and the Acculturation Dysfunction. As is depicted in Figure 8, the Authoritarian Family is predicting the Negative Existential Position (.15); the Authoritarian Cultural milieu predicts it even more strongly (.31). Both these predictors were found correlated (.38) (which was also expected to be found). The Acculturation Dysfunction variable was found to be predicted by the Negative Existential Position (.22). It was found that the Authoritarian Family predicts the Acculturation Dysfunction in a negative way (-.13), but there was no evidence found about the Authoritarian Culture as a predictor for the Acculturation Dysfunction.

\section{Discussion}

The hypothesis that the Negative Existential Position is more articulated among individuals with authoritarian socialization background was confirmed: the highest mean scores on the Negative Existential Position were obtained among the respondents of Turkish origin, the second highest was the Ex-Soviet respondents and the respondents from Western countries scored the least. The hypothesis that individuals with authoritarian background experience more difficulties within acculturation than those without authoritarian background was confirmed as well.

Calculated as a sum of positive answers with regard to any of the four statements about acculturation attitudes in the four acculturation domains (family, language, culture, holidays), style of acculturation results show the most preferred style of acculturation was Integration, Assimilation was rated lowest and Marginalization and Separation fell in between. This trend is in line with numerous empirical findings made in diverse cultures and diverse immigrant groups all over the world. (Berry, 1997; Piontkowski, Florack, Hölker \& Obdrzalek, 2000; Neto, 2002, Phinney, 2003; Hsiao \& Wittig, 2008)

An important finding was made on the interplay between - on the one side - four types of the Existential 
Positions and the (corresponding) Berry's styles of acculturation: the correlations were all positive, strong or moderate, statistically significant or close to it. It supports the idea about the conceptual closeness of the concepts which in the first case is individual construct or an attitude toward Self, and in the second case an attitudinal construct about a culture (its own versus another within acculturation).

With regard to the predictive role of the variables under investigation, the Positive Existential Position showed predictability power for Integration (.23) for the total immigrant sample.

The hypothesis that the Negative Existential Position in general serves as a predictor for 'inharmonious' styles of acculturation has found support, although not equally strong support for each of the subsamples. Thus, the Negative Existential Position was found to be a good predictor of Separation among the Turkish and Ex-Soviet respondents (groups with authoritarian background), but not among the Westerners.

As structural equation modelling showed, the Negative Existential Position plays a 'fostering' role with regard to Separation, which in its turn is a good predictor of the Acculturation Dysfunction. Notable is that the Negative Existential Position had a significant direct effect on Acculturation Dysfunction among respondents from Western countries.

\section{Conclusion}

This research was a first of its kind, where the acculturation features (acculturation styles and notorious difficulties experienced by certain groups of immigrants) were approached and explored using the Transactional Analysis paradigm and the concept of Existential Position. Thus, this research, along with answering certain questions, gives valuable information on acculturation features of immigrants with authoritarian background and on the influence of such a background on the character of their acculturation process.

This information can be useful for policymakers within the state or community immigration policy-making process in order to provide more efficient policies for specific groups of immigrants and the development of healthy intercultural dialogue between a receiving society and newcomers as well as among different groups of newcomers and a receiving society: there are conflicts especially between the groups of immigrants with authoritarian background. One of the notorious distinctive characteristics of individuals with authoritarian backgrounds is their tendency to divide people into 'ingroups' and 'out-groups', to perceive the world as a dangerous, unfriendly place, and to fight with 'outgroups'; this is of exceptional significance in the context of acculturation and the multicultural globalizing world as it is now.
The Authoritarian Personality, as the type of individuality which is fostered by an authoritarian background, was only partially mentioned in this article due to the focus on the relationships between Berry's concept and the concept on Existential Position. Nevertheless, its significance is crucial for understanding the phenomena of unsuccessful acculturation of immigrants with authoritarian background, which is documented in numerous studies (Mayer, Fuhrer \& Uslucan, 2005; Pfeiffer, Wetzels \& Enzmann, 1999; Pfeifer \& Wetzels, 2000; Pfeifer, 2001). The entire report on the Authoritarian Personality studied using a transactional analysis approach, as well as a report on examination of the relationships between authoritarian background variables and acculturation variables is given in the dissertation thesis (Kornyeyeva, O. 2010).

Another issue evoked by this research is that of psychometrics traditionally used in acculturation research. Berry's fourfold approach to acculturation has evoked a vivid debate since the middle of 1990s (Rudmin, 2003, 2006). Under criticism is the point that Integration has been found, according to numerous empirical studies (Rudmin, 2003), not to negatively correlate strongly enough with psychological maladaptation of immigrants. This may, of course, be caused by unsatisfactory psychometric instruments used in empirical acculturation research.

Poor validity of acculturation psychometrics is also reported in the literature (Rudmin, 2003). While the psychometrical body of acculturation research, indeed, needs to be improved, from the theoretical point of view transactional analysis offers a sufficient basis for the fourfold approach to acculturation. Thus, the Positive Existential Position of an individual is regarded as a prerequisite for harmonious, cooperative relationships with others and a predicate for an ability to solve possible problems in relationships (Berne, 1964; Steiner, 1974, Stewart \& Joines, 1987); Integration as a style of acculturation with both positive attitudinal components seems to be the healthiest, non-conflict style of acculturation as well. Similar tendencies can be traced with regard to the three 'inharmonious' styles of acculturation and their phenomenological closeness with the Negative Existential Positions; the research reported here offers evidence on this.

Further elaboration is needed on the TA-based psychometric instruments in empirical social-psychological research. The most problematic issue seems to be the 2-dimensional nature of the constructs (Existential Positions) and the correspondent psychometrical items used in field research. As was mentioned above, it is difficult (if not mathematically impossible) to estimate in which proportion are the attitudes toward Self and Others in an answer on the variable, which for statistical purpose was calculated as two items (one item on ' $l$ ' and one items on 'You'). Such a methodological problem may be successfully solved in cooperation with professional mathematicians/statisticians. 
This research under the title "Authoritarian Socialization Experience and Acculturation Dysfunction among Young Immigrants to Western Europe: The Role of a Negative Existential Position" was conducted by Lena Kornyeyeva at Jacobs University Bremen, Germany, during the years 2006-2009, Professor Klaus Boehnke being the primary supervisor. It was supported by the Open Society Institute and the Deutsche Akademische Austauschdienst.

Lena Kornyeyeva PhD holds MA-equivalent degrees in Social Psychology and Psychological Counselling. In 2010 she received her PhD in Psychology from Jacobs University Bremen, Germany. Her research interests lie in the fields of social and developmental psychology, acculturation and authoritarianism. She can be contacted on kornyeyeva@imbdp.de

\section{References}

Ben-Shalom, U. \& Horenczyk, G. (2003). Acculturation Orientations: A Facet Theory Perspective on the Bidimensional Model. Journal of Cross-Cultural Psychology; 34: 176-188.

Berne, E. (1964) Beyond Games and Scripts (C. Steiner \& C. Kerr, Eds.). New York: Ballantine Books

Berry, J.W. (1980). Social and cultural change. In H. C. Triandis, \& R. W. Brislin (Eds.), Handbook of cross-cultural psychology: Social psychology 5, 211-279). Boston: Allyn and Bacon.

Berry, J.W. (1984). Cultural relations in plural societies: Alternatives to segregation and their sociopsychological implications. In: Miller, N./Brewer, M. (Eds.): Groups in Contact. New York: Academic Press.

Berry, J.W., Kim, U., Minde, T., \& Mok, D. (1987) Comparative studies of acculutuarative stress. Intenational Migration Review. 21, 491-511.

Berry, J.W., \& Kim, U. (1988). Acculturation and mental health. In P.R. Dasen, J.W. Berry \& N. Sarorius (Eds.), Health and Cross-Cultural Psychology: Toward Applications. Newbury Park, California: Sage, 207-236.

Berry, J.W., Kim, U., Power, S., Young, M., \& Bujaki, M. (1989). Acculturation attitudes in plural societies, Applied Psychology, 38, 185-206.

Berry, J.W. (1989). Psychology of acculturation. In J. Berman (Ed.), Nebraska Symposium on Motivation Vol. 37 Lincoln: University of Nebraska, 201-234.

Berry, J.W. (1990) Psychology of accultaruaruon on Berman, J. (ed) Nebraska Symposium on Motivation 1989. Vol 37 Cross-culural perspective (201-234) Lincoln, NE: University of Nebraska Press
Berry, J.W. (1997). Immigration, acculturation, and adaptation. Applied Psychology: An International Review, 46, 5-34.

Eurostat (2006)

http://www.salzburg.gv.at/themen/gv/migration/migrationsberic ht 2006eurostat.htm 7/10/2006

Fuhrer U. \& Uslucan, H-H. (2005). Familie, Akkulturation \& Erziehung. Stuttgart: Kohlhammer.

Fuhrer, U. \& Uslucan, H-H. (Hrsg.) (2005). Akkulturation, Familie und Erziehung: Migration zwischen Eigen- und Fremdkultur. Stuttgart: Kohlhammer.

Guild, E. \& van Selm, J. (Ed.) (2005). International Migration and Security: Opportunities and Challenges. London/New York Routledge.

Hsiao, J. \& Wittig, M. A. (2008). Acculturation Among Three Racial/Ethnic Groups of Host and Immigrant Adolescents. American Journal of Community Psychology. December; 42(34): Volume 42, Numbers 3-4, 286-297.

Kälin, K. \& Müri, P. (1993) Sich und andere Fuhren, Psychologie für Führungskräfte und Mitarbeiter. 7 edition (in German) Thun:Ott-Verlag

Kornyeyeva, O. (2010). Authoritarian Socialization Experience and Acculturation Dysfunction among Young Immigrants to Western Europe: The Role of a Negative Existential Position. (Doctoral Dissertation) available as an e-book via http://www.aschenbeckmedia.de/index.php/lesen-unddenken/theorie/authoritarian-socialization-experience-andacculturation-dysfunction-among-young-immigrants-towestern-europe-the-role-of-a-negative-existential-position.html

Kornyeyeva, O. (in print). Studying Authoritarianism using Transactional Analysis Theory: The Role of the Negative Existential Position in Authoritarian Personality Formation.

Lderer, G., Nerger, J., Rippl, S., Schmidt, P. \& seipel, C. (1991) Autoritismus unter Jugendlichen der ehemaligen DDR (in German) Deutschland Archiv 24, 587-596

Massey R. (1987). Transactional Analysis and the Social Psychology of Power: Reflections Evoked by Jacobs' Autocratic Power. Transactional Analysis Journal, 17(3), July, 59 - 71.

Mayer, S., Fuhrer, U. \& Uslucan, H.-H. (2005). Akkulturation und intergenerationale Transmission von Gewalt in Familien türkischer Herkunft. Psychologie in Erziehung und Unterricht, 52, 168-185.

Mellor, K. \& Schiff, E. (1975). Discounting. Transactional Analysis Journal, 5 (3)292-302.

Neto, F. (2002) Acculturation strategies among adolescents from immigrant families in Portugal. International Journal of Intercultural Relations. 26,( 1) February 17-38. 
Pfeiffer, C. \& Wetzels, P. (2000). Junge Turken als Tater und Opfer von Gewalt. Kriminologisches Forschungsinstitut Niedersachsen. Forschungsbericht Nr. 81.

Pfeiffer, C. (2001). Gewalt entsteht durch Gewalt. Wie kann der Teufelskreis durchbrochen werden? In W. Deutsch \& M. Wenglorz (Hrsg.), Zentrale Entwicklungsstörungen bei Kindern und Jugendlichen. Aktuelle Erkenntnisse über die Entstehung, Therapie und Prävention 164- 188 Stuttgart: Klett-Cotta.

Pfeiffer, C., Wetzels, P. \& Enzmann, D. (1999). Innerfamiliare Gewalt gegen Kinder und Jugendliche und ihre Auswirkungen. Kriminologisches Forschungsinstitut Niedersachsen. Forschungsbericht Nr. 80.

Phinney, J. (2003). Ethnic Identity and Acculturation. In K Chun, P. Ball, \& Marin, G. (Eds.), Acculturation: Advances in theory, measurement, and applied research 63-81 Washington, DC: American Psychological Association.

Piontkowski, U., Florack, A., Hölker, P. \& Obdrzalek, P. (2000). Predicting acculturation attitudes of dominant and nondominant groups. International Journal of Intercultural Relations, 24, 1-26.

Redfield, R. Linton, R., \& Herskovits, M.J. (1936). Memorandum for the study of acculturation. American Anthropologist, 38, 149 - 152.

Rudmin, F.W. (2003). Critical history of the acculturation psychology of assimilation, separation, integration, \& marginalization. Review of General Psychology 7, 3-37.

Rudmin, F.W. (2006). Debate in science: The case of acculturation. In AnthroGlobe Journal

http://malinowski.kent.ac.uk/docs/rudminf acculturation 06120 4.pdf 14/07/2008
Ryder, A., Alden, L. \& Paulhus, D. (2000) Is acculturation unidimentional or bidimentional? A head-to-head comparison in the prediction of personality, self-identity, and adjustment. Journal of Personality and Social Psychology, 79, 49-65.

Sam, D.L \& Berry, J.W (Eds). (2006). Cambridge handbook of acculturation psychology. Cambridge: Cambridge University Press.

Sayegh, L. \& Lasry, J-C. (1993), Immigrants' Adaptation in Canada: Assimilation, Acculturation, and Orthogonal Identification. Canadian Psychology, 34 (1), 98-109.

Spencer, S. (1994). Immigration as an economic asset: the German experience. Institute for Public Policy Research (London, England) Stoke-on-Trent: IPPR/Trentham.

Spencer, S. \& Rudiger, A. (2003) Social Integration of Immigrants and Ethnic Minorities, Policies to Combat Discrimination. OECD/European Commission

Steiner, C. (1974) Scripts People Live. New York: Grove Press

Stewart, I. \& Jones, V. (1987). TA Today. Nottingham and Chapel Hill, Lifespace Publishing.

Wallen, G.R., Feldman, R.H.L. \& Anliker, J. (2002) Measuring Acculturation among Central American Women Using a Brief Language Scale. Journal of Immigrant Health 42 (2) 95-102

Ward, C. \& Kennedy, A. (1999) The measurement of sociocultural adaptation. International Journal of Intercultural Relations. 23 (4) 659-677. 